\title{
Factors associated with clinical and radiological status on admission in patients with aneurysmal subarachnoid hemorrhage
}

Daniel W. Zumofen ${ }^{1,2} \cdot$ Michel Roethlisberger $^{1} \cdot$ Rita Achermann $^{3} \cdot$ Schatlo Bawarjan $^{4} \cdot$ Martin N. Stienen $^{5}$. Christian Fung $^{6}$ - Donato D'Alonzo ${ }^{7}$. Nicolai Maldaner ${ }^{5} \cdot$ Andrea Ferrari $^{8} \cdot$ Marco V. Corniola $^{9}$ - Daniel Schoeni ${ }^{6}$. Johannes Goldberg ${ }^{6}$. Daniele Valsecchi ${ }^{10}$. Thomas Robert $^{10} \cdot$ Rodolfo Maduri $^{11}$ - Martin Seule ${ }^{8}$. Jan-Karl Burkhardt ${ }^{12}$ - Serge Marbacher ${ }^{7}$. Philippe Bijlenga ${ }^{9} \cdot$ Kristine A. Blackham $^{2}$ - Heiner C. Bucher ${ }^{3}$. Luigi Mariani ${ }^{1} \cdot$ Raphael Guzman ${ }^{1}$ • on behalf of the Swiss SOS Study Group

Received: 19 December 2017 / Revised: 25 January 2018 / Accepted: 28 January 2018

(C) Springer-Verlag GmbH Germany, part of Springer Nature 2018

\section{Abstract}

Grading scales yield objective measure of the severity of aneurysmal subarachnoid hemorrhage and serve as to guide treatment decisions and for prognostication. The purpose of this cohort study was to determine what factors govern a patient's disease-

Daniel W. Zumofen and Michel Roethlisberger contributed equally to this work.

On behalf of the Swiss SOS Study Group Members and collaborators of the Swiss SOS Study Group are listed in the appendix

Electronic supplementary material The online version of this article (https://doi.org/10.1007/s10143-018-0952-2) contains supplementary material, which is available to authorized users.



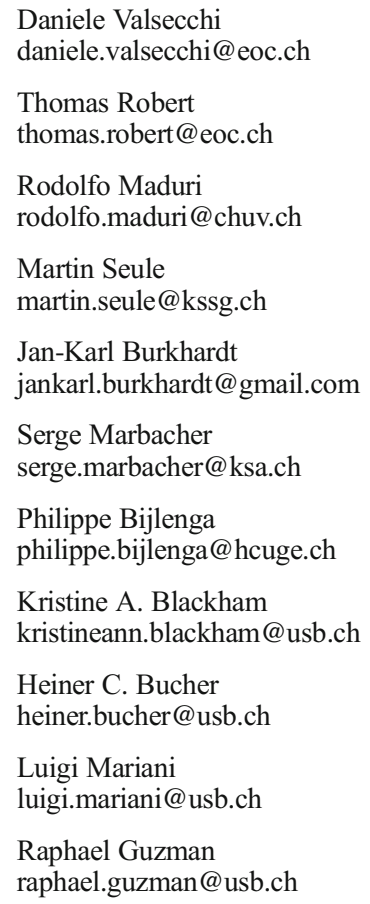

Extended author information available on the last page of the article 
specific admission scores in a representative Central European cohort. The Swiss Study of Subarachnoid Hemorrhage includes anonymized data from all tertiary referral centers serving subarachnoid hemorrhage patients in Switzerland. The 2009-2014 dataset was used to evaluate the impact of patient and aneurysm characteristics on the patients' status at admission using descriptive and multivariate regression analysis. The primary/co-primary endpoints were the GCS and the WFNS grade. The secondary endpoints were the Fisher grade, the presence of a thick cisternal or ventricular clot, the presence of a new focal neurological deficit or cranial nerve palsy, and the patient's intubation status. In our cohort of 1787 consecutive patients, increasing patient age by 10 years and low pre-ictal functional status ( $\mathrm{mRS} 3-5$ ) were inversely correlated with "high" GCS score (GCS $\geq 13$ ) (OR 0.91, 95\% CI 0.84-0.97 and OR 0.67, 95\% CI 0.31-1.46), "low" WFNS grade (grade VI-V) (OR 1.21, 95\% CI 1.04-1.20 and OR 1.47, 95\% CI 0.66-3.27), and high Fisher grade (grade III-IV) (OR 1.08, 95\% CI 1.00-1.17 and OR 1.54, 95\% CI 0.554.32). Other independent predictors for the patients' clinical and radiological condition at admission were the ruptured aneurysms' location and its size. In sum, chronological age and pre-ictal functional status, as well as the ruptured aneurysm's location and size, determine the patients' clinical and radiological condition at admission to the tertiary referral hospital.

Keywords Aneurysm $\cdot$ Subarachnoid hemorrhage $\cdot$ Age $\cdot$ Clinical presentation $\cdot$ Radiological presentation

\section{Introduction}

Aneurysmal subarachnoid hemorrhage (aSAH) accounts for about $5 \%$ of strokes but has a disproportionate mortality rate of 40 to $60 \%$ [1-3]. Aneurysm characteristics such as location, size, and morphology govern an intracranial aneurysm's tendency to bleed $[4,5]$, while outcome following aneurysm rupture is determined by factors that include patient age and severity of the bleed [6,7]. The severity of aSAH is assessed by a series of grading scales that yield objective measure of a patient's clinical and radiological condition at admission. In routine clinical practice, these aSAH-specific indexes serve as to guide treatment decisions and for prognostication [8-10]. They include in particular the World Federation of Neurosurgical Societies (WFNS) classification [11] with the GCS score [12] as its main component [13]. In addition, radiological scores such as the Fisher grading scale [14] and the presence or absence of a thick cisternal or ventricular blood clot on CT scan serve as to predict the risk of developing hydrocephalus and/or vasospasm with or without delayed cerebral ischemia (DCI) [15-17]. Although used in everyday practice, aSAH-specific indexes were often based on poorly representative data from a today's point of view, which may lead to conflicting results as to the nature and the extent of associations in contemporary Western populations defined by increased health condition and life expectancy [6, 18-22].

The purpose of the present nationwide cohort study was to investigate what factors determine the patients' clinical and radiological status at the time point of initial admission to the tertiary referral hospital in a representative Central European cohort of aSAH patients. Only few registries offer the combination of a dedicated nationwide all including registration of aSAH patients with highly detailed data acquisition that is not part of more general stroke registries [23-28]. The Swiss Study of Subarachnoid Hemorrhage (SOS) database provides the exceptional property that all aSAH in Switzerland are treated within one of the participating centers, hence to a certain extent representing the nations' true epidemiology [29]. In sum, we expect our finding to apply eventually to all Western countries with typical aging demographics and with a similar healthcare system, meaning with universal access and coverage.

\section{Materials and methods}

\section{Patient registry}

The SOS registry was implemented in 2009 , and study details were previously published [29]. Internal Review Board and Ethical committee approval was obtained for all participating centers (under the supervision of the Geneva ethical committee board no. 11-233R, NAC 11-085R). Most local Ethic Committees waived the need for obtaining written informed consent (justification: disproportionality). Written informed consent was obtained however from all participating patients if the local Ethic Committee had requested it. As of 2014 (implementation of the new Swiss Human Research Act), written informed consent was obtained from all participating patients in all participating centers. This study was a retrospective analysis of a prospectively collected database and does not require clinical trial registration.

\section{Study centers and data collection}

Patients with aSAH in Switzerland are cared for in one of the eight accredited neurovascular referral centers (university hospitals of Basel, Bern, Geneva, Lausanne, and Zurich and the cantonal hospitals of Aarau, Lugano, and St. Gallen). All eight centers contributed data to the Swiss SOS registry [29]. Clinical and radiological assessment at admission was performed at each individual center with the center-specific standard procedures for the management and treatment of aSAH 
[30]. A predefined set of clinical and radiological variables were prospectively pooled in a secured, pseudonymized web-based registry for the present study (secuTrial®, InterActive Systems GmbH, Berlin, Germany) [29].

\section{Study population}

Data was collected for all patients with aSAH from a documented ruptured intracranial aneurysm from 2009 to 2014 that were admitted to one of the participating centers. Patients were excluded if they had non-aneurysmal SAH, an angiographically negative SAH, SAH of another confirmed cause, or no available information regarding the source of SAH.

\section{Study variables}

For the present study, the following variables were extracted and anonymized from the SOS database: patient characteristics (age, gender, and pre-aSAH mRankin scale score (mRS) [31]), aneurysm characteristics (location and maximal diameter of the ruptured index aneurysm, and any unruptured bystander aneurysm(s) aneurysm multiplicity), admission scores (GCS score, WFNS grade, Fisher grade), and additional variables (new neurological deficits (ND), new cranial nerve palsies (CNP), intubation status at admission, and presence of a thick cisternal or ventricular blood clot larger than $5 \times 3 \mathrm{~mm}$ in the axial plane on the admission CT scan).

\section{Endpoints}

The primary/co-primary endpoints were defined as the GCS score and the WFNS grade at the time point of initial admission to the tertiary referral hospital. The secondary endpoints were defined as the Fisher grade, the presence or absence of a thick blood clot on admission CT scan, the presence or absence of a new neurological deficit or new cranial nerve palsy on admission exam, and the patient's intubation status at the time point of initial admission to the tertiary referral hospital.

\section{Statistical analysis}

Statistical analysis was performed with R (R Foundation for Statistical Computing. Release date 2014. R for Windows. Version 3.0.3. Vienna, Austria). For the multivariate mixed effect logistic regression model, univariate models were calculated to test for associations between the variable of interest and independent variables (see study variables above). For this purpose, data was dichotomized into "high" GCS score (GCS $\geq 13$ ) versus "low" GCS score (GCS $\leq 12$ ), high WFNS grade (WFNS grade IV-V) versus low WFNS grade (WFNS grade I-III), and high Fisher grade (Fisher grade III-IV) versus low Fisher grade (Fisher grade I-II). Covariates with a $p$ value $\leq 0.2$ were included in an initial multivariate model and model selection based on likelihood ratio tests. The Akaike information criterion was performed to reduce the set of covariates. For confounder-adjusted analysis, sex, pre-aSAH mRS, anterior vs. posterior circulation aneurysm, and a "center" variable were entered into either a cumulative or a logistic linear mixed model depending on the type of the outcome. To account for non-independence of the measurements of the same center, a random center intercept was included in the statistical models. For multiple testing, post hoc testing was performed using Bonferroni-Holm [32] method. To account for missing values, all statistical models were computed for a dataset of complete cases, for each covariate univariate, and on an imputed dataset, for which it was assumed that the missing values were missing at random (MAR). Five imputed datasets were produced by generating a random forest for each, with a different value for the random forest number generator for each dataset (nonparametric missing value imputation using random forest, r: package missForest). Statistical models were then computed for each imputed dataset, and Rubin's rule was applied to combine the estimates. The complete correlation tables are provided in Suppl. Data Table 1. Forrest plots are provided in Suppl. Data Fig. 1. Statistical significance was defined as $p \leq 0.05$.

\section{Results}

The locked SOS dataset 2009-2014 included 1787 patients. A detailed patient inclusion profile that specifies the number of patients assessed for each of the tested variables is provided in Fig. 1.

\section{Baseline characteristics}

The mean age at ictus was $55.9(\mathrm{SD} \pm 13.2)$ years. A majority of patients were in the age range 40 to 64 years. The sex ratio was $1.52(\mathrm{~F} / \mathrm{M})$. Details are provided in Table 1.

Table 1 Baseline characteristics

Study population

\begin{tabular}{llll}
\hline$n$ & 1787 & & \\
Age at admission & Total & Females & Males \\
Mean & 55.9 years $(\mathrm{SD} \pm 13.2)$ & 57 years & 53.7 years \\
Age groups & $n(\%)$ & $n(\%)$ & $n(\%)$ \\
0-39 years & $202(11.3)$ & $108(9.2)$ & $94(15.3)$ \\
40-64 years & $1175(65.5)$ & $764(64.9)$ & $409(66.7)$ \\
65-74 years & $264(14.7)$ & $191(16.2)$ & $73(11.9)$ \\
$\geq 75$ years & $152(8.5)$ & $115(9.8)$ & $37(6.0)$ \\
\hline
\end{tabular}


Fig. 1 Patient inclusion profile

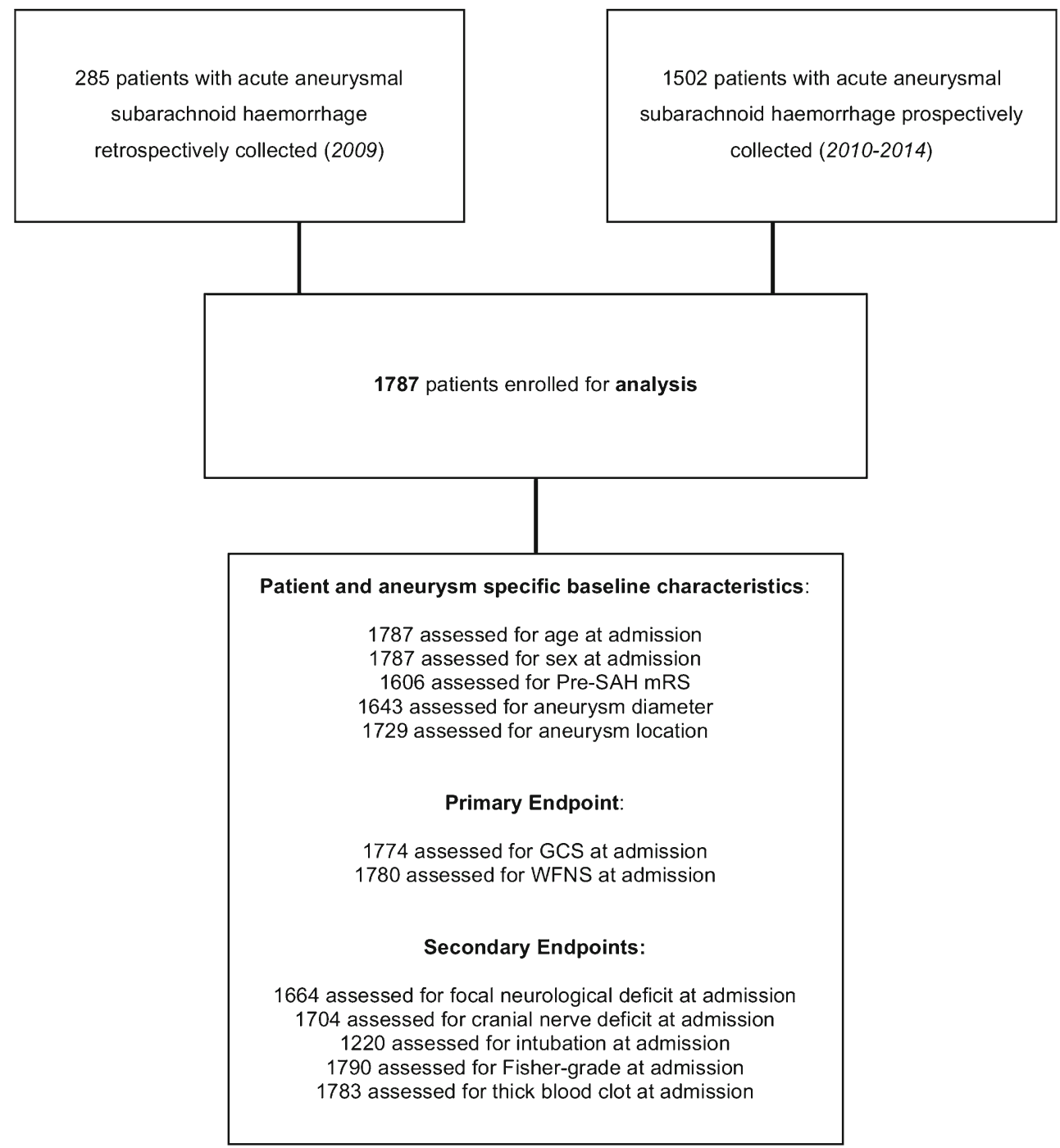

\section{Cumulative empirical distributions}

The number of patients in each severity level of the different admission scores, broken down for different age groups (if applicable), is provided in Table 2. Overall, the proportion of patients with no pre-existing disability $(\mathrm{mRS}=0)$ decreased with increasing patient age, while the proportion of patients with "no significant" or "slight" disability ( $\mathrm{mRS}=1-2)$ simultaneously rose (Suppl. Data Fig. 2A). Similarly, the proportion of patients who presented with a high GCS score and with a high WFNS grade decreased with increasing patient age. Nonetheless, more than half of patients older than 75 years had favorable clinical admission scores if the latter were defined as GCS 13-15 and WNFS I-III (Suppl. Data Fig. 2B and C). With regard to the radiological scores, the proportional distribution of patients by Fisher grade remained about constant with increasing patient age (Suppl. Data Fig. 2D).

A summary breakdown of the aSAH causing aneurysms' characteristics is provided in Table 3. Overall, more than three quarters of the aSAH-causing aneurysms were located in the anterior (carotid) circulation with ruptured anterior communicating artery (ACommA) aneurysms being the most frequent ( $n=546 / 1787 ; 30.6 \%)$. The largest proportion of aneurysms was $\geq 7 \mathrm{~mm}$ in maximal diameter $(n=717 / 1787: 40.1 \%)$. The proportion of patients who presented with a "high GCS score" and a "good WFNS grade" was lower in the posterior circulation aneurysm group (Fig. 2a, b) and in those patients whose aneurysm was larger than $7 \mathrm{~mm}$ in maximal diameter (Fig. 2c, d).

\section{Correlations}

Impact of patient characteristics: increasing patient age by steps of 10 years was correlated with low GCS score. A patient's risk for presenting with a low GCS increasing by $10.5 \%$ per each 10 years of additional age. Increasing patient age by 10 years was also correlated with low WFNS grade, with high Fisher grade, with presence of a large blood clot, and with 
Table 2 Admission scores

\begin{tabular}{|c|c|c|c|c|c|}
\hline & $\begin{array}{l}\text { Total } \\
n(\%)\end{array}$ & $\begin{array}{l}\text { Age } 0-40 \text { years } \\
n(\%)\end{array}$ & $\begin{array}{l}\text { Age } 40-65 \text { years } \\
n(\%)\end{array}$ & $\begin{array}{l}\text { Age } 65-75 \text { years } \\
n(\%)\end{array}$ & $\begin{array}{l}\text { Age } \geq 75 \text { years } \\
n(\%)\end{array}$ \\
\hline \multicolumn{6}{|c|}{ Pre-SAH mRS } \\
\hline mRS 0 & $1392(77.9)$ & $171(95)$ & $935(89)$ & $195(82.3)$ & $91(65.5)$ \\
\hline mRS 1-2 & $193(10.8)$ & $8(4.4)$ & $105(10)$ & $39(16.5)$ & $41(29.5)$ \\
\hline mRS $3-5$ & $21(1.2)$ & $1(0.6)$ & $10(1)$ & $3(1.2)$ & $7(5)$ \\
\hline Missing $^{a}$ & $181(10.1)$ & & & & \\
\hline Total & $1787(100)$ & $180(11.2)$ & $1050(65.4)$ & $237(14.8)$ & $139(8.7)$ \\
\hline \multicolumn{6}{|l|}{ GCS } \\
\hline GCS 3-6 & $485(27.5)$ & $45(22.5)$ & $304(26.6)$ & $95(35.7)$ & $41(26.6)$ \\
\hline GCS 7-12 & $190(10.8)$ & $15(7.5)$ & $121(10.6)$ & $31(11.7)$ & $23(14.9)$ \\
\hline GCS $13-15$ & $1090(61.8)$ & $140(70)$ & $720(62.9)$ & $140(52.6)$ & $90(58.4)$ \\
\hline Missing $^{\mathrm{a}}$ & $22(1.2)$ & & & & \\
\hline Total & $1765(100)$ & $200(11.3)$ & 1145 (64.9) & $266(15.1)$ & $154(8.7)$ \\
\hline \multicolumn{6}{|l|}{ WFNS grade } \\
\hline I-III & $1104(62.3)$ & $140(70)$ & $729(63.4)$ & $142(53.2)$ & $93(60.4)$ \\
\hline IV-V & $667(37.7)$ & $60(30)$ & $421(36.6)$ & $125(46.8)$ & $61(39.6)$ \\
\hline Missing $^{\mathrm{a}}$ & $16(0.9)$ & & & & \\
\hline Total & $1771(100)$ & $200(11.3)$ & $1150(64.9)$ & $267(15.1)$ & $154(8.7)$ \\
\hline \multicolumn{6}{|l|}{ Fisher grade } \\
\hline I & $54(3.0)$ & & & & \\
\hline II & $163(9.1)$ & & & & \\
\hline III & $989(55.3)$ & & & & \\
\hline IV & $576(32.5)$ & & & & \\
\hline \multirow[t]{2}{*}{ Missing $^{\mathrm{a}}$} & $5(0.3)$ & & & & \\
\hline & $\begin{array}{l}\text { Neurological deficit } \\
n(\%)\end{array}$ & $\begin{array}{l}\text { Cranial nerve palsy } \\
n(\%)\end{array}$ & $\begin{array}{l}\text { Thick blood clot } \\
n(\%)\end{array}$ & $\begin{array}{l}\text { Intubated } \\
n(\%)\end{array}$ & \\
\hline Yes & $453(27.1)$ & $345(20.7)$ & $1565(87.6)$ & $389(31.9)$ & \\
\hline Missing $^{\mathrm{a}}$ & $123(6.9)$ & $83(4.6)$ & $4(0.2)$ & $567(31.7)$ & \\
\hline
\end{tabular}

Age group-related number of patients in each severity level of the different admission scores

${ }^{\mathrm{a}}$ No information available

presence of ND. These findings remained significant after accounting for multiple testing (Table 4, Suppl. Data Table 1, Suppl. Data Fig. 1). The impact of lower pre-ictal functional status largely paralleled the impact of increasing patient age. However, our study remained underpowered to estimate the effect (Suppl. Data Table 1).

Impact of aneurysm characteristics: vertebral artery (VA) and basilar artery (BA) location were correlated with low GCS score and low WFNS grade, as well as with the intubation status "intubated." In contrast, middle cerebral artery (MCA) location was correlated with "good" WFNS grade and with high Fisher grade. In addition, MCA location was correlated with the presence of a ND and with the presence of a CNP. Aneurysm size $\geq 7 \mathrm{~mm}$ when compared to $\leq 5 \mathrm{~mm}$ was correlated with low GCS score, with low WFNS grade, and with the presence of a CNP. These findings remained significant after accounting for multiple testing (Table 4, Suppl. Data Table 1, Suppl. Data Figure 1).

\section{Discussion}

While previous work focused on outcome analysis, the purpose of the present nationwide cohort study was to investigate what factors determine the patients' clinical and radiological status at the time point of initial admission to the tertiary referral hospital $[7,33]$. In line with a previous report, we found that patient age and lower pre-ictal functional status were both independent predictors for worse clinical and radiological status at the time of a patient's initial admission to the tertiary neurovascular referral hospital [7]. In other words, they both independently predicted worse admission scores, which in turn foretells poor outcome following aSAH [8-10]. In contrast to previous work, we also modeled specific aneurysm-related prognostic factors including detailed aneurysm location and size [7]. We found that certain specific locations of the aSAH causing aneurysm particularly in the posterior circulation (e.g., VA and BA), as well as increasing 

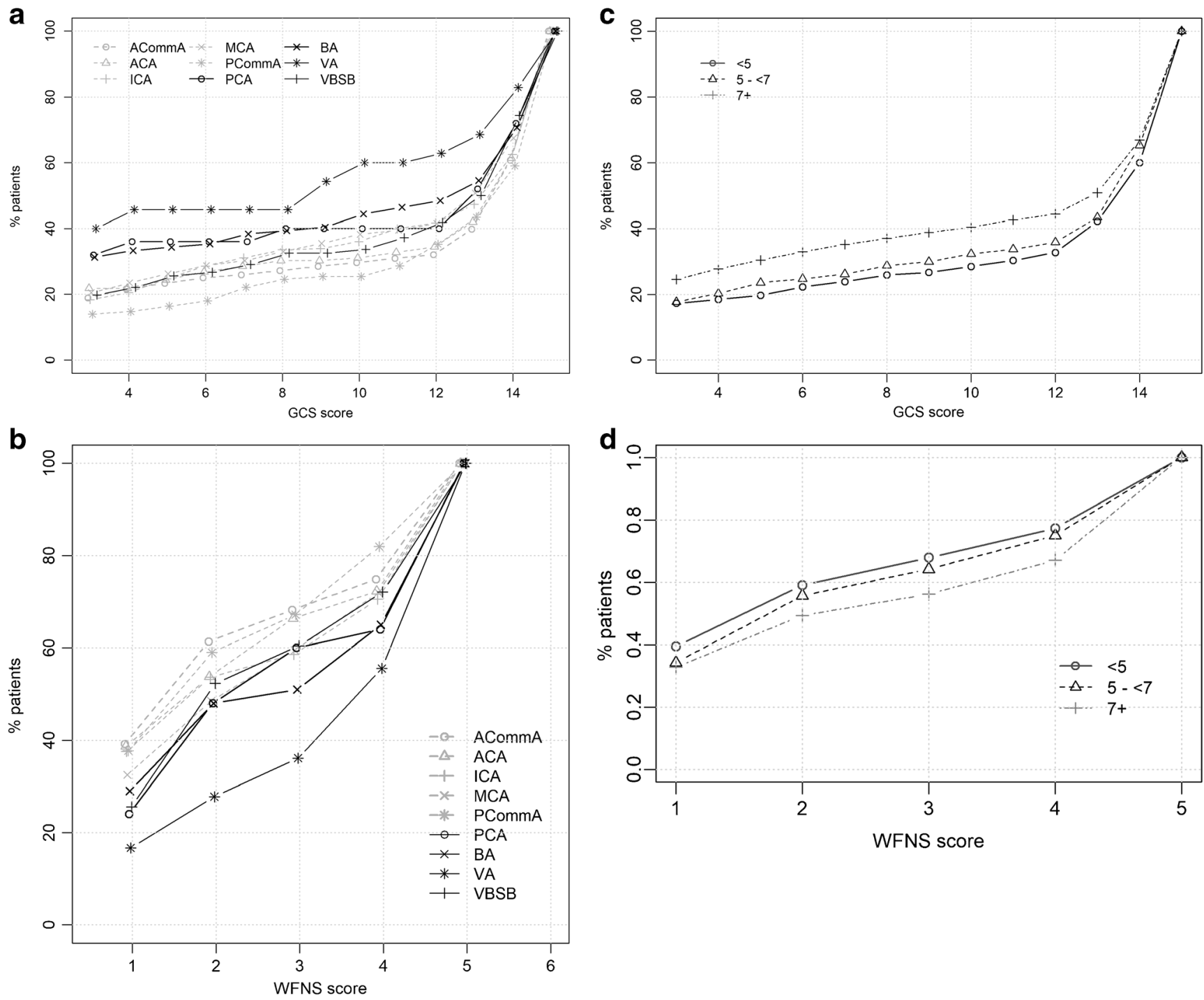

Fig. 2 Empirical cumulative distribution. a Cumulative GCS distribution by index aneurysm location. b Cumulative WFNS grade distribution by index aneurysm location. c Cumulative GCS grade distribution by index aneurysm size (maximal diameter in millimeters). d Cumulative WFNS grade distribution by index aneurysm size (maximal diameter in millimeters). ACommA anterior communicating artery, $A C A$ anterior

cerebral artery, ICA internal carotid artery, $M C A$ middle cerebral artery, $P C o m m A$ posterior communicating artery, $P C A$ posterior cerebral artery, $B A$ basilar artery, $V A$ vertebral artery, $V B S B$ vertebrobasilar side branches including the superior cerebellar artery (SCA), the anterior inferior cerebellar artery (AICA), and the posterior inferior cerebellar artery (PICA)

aneurysm size ( $\geq 7 \mathrm{~mm}$ ), were additional independent predictors for worse clinical and radiological status at admission to

the tertiary referral hospital (Table 4, Suppl. Data Table 1, Suppl. Data Fig. 1).

Table 3 Frequency table

\begin{tabular}{|c|c|c|c|c|c|}
\hline Aneurysm size distribution & $\begin{array}{l}\text { Total } \\
n(\%)\end{array}$ & $\begin{array}{l}<5 \mathrm{~mm} \\
n(\%)\end{array}$ & $\begin{array}{l}5-<7 \mathrm{~mm} \\
n(\%)\end{array}$ & $\begin{array}{l}\geq 7 \mathrm{~mm} \\
n(\%)\end{array}$ & $\begin{array}{l}\text { Missing }^{\mathrm{a}} \\
n(\%)\end{array}$ \\
\hline Anterior (carotid) circulation & $1479(82.8)$ & $420(28.4)$ & $367(24.8)$ & $623(42.1)$ & $69(4.7)$ \\
\hline Posterior (vertebrobasilar) circulation & $250(14.0)$ & $79(31.6)$ & $59(23.6)$ & $94(37.6)$ & $18(7.2)$ \\
\hline Missing $^{\mathrm{a}}$ & $58(3.2)$ & $1(1.7)$ & $0(0)$ & $0(0)$ & $57(98.3)$ \\
\hline Total & $1787(100)$ & $500(28)$ & $426(23.8)$ & $717(40)$ & $144(8.1)$ \\
\hline
\end{tabular}

A detailed breakdown of aneurysms by size and by location will be published separately

${ }^{\mathrm{a}}$ No information available 
Table 4 Correlation tables

\begin{tabular}{|c|c|c|c|c|c|c|c|c|c|}
\hline & MV OR & $p$ values & CI $(95 \%)$ & UV OR & $p$ values & CI (95\%) & IMP OR & $p$ values & CI $(95 \%)$ \\
\hline \multicolumn{10}{|l|}{ High GCS score } \\
\hline Age & 0.91 & 0.006 & $0.84-0.97$ & 0.90 & 0.001 & $0.84-0.96$ & 0.91 & 0.003 & $0.85-0.97$ \\
\hline MCA & 0.78 & 0.053 & $0.60-1.00$ & 0.75 & 0.014 & $0.59-0.94$ & 0.76 & 0.027 & $0.60-0.97$ \\
\hline VA & 0.32 & 0.002 & $0.15-0.65$ & 0.34 & 0.001 & $0.19-0.63$ & 0.36 & 0.001 & $0.20-0.66$ \\
\hline BA & 0.58 & 0.011 & $0.38-0.89$ & 0.56 & 0.003 & $0.39-0.83$ & 0.58 & 0.006 & $0.39-0.86$ \\
\hline PICA/AICA/SCA & 0.61 & 0.027 & $0.40-0.95$ & 0.70 & 0.077 & $0.47-1.04$ & 0.68 & 0.057 & $0.46-1.01$ \\
\hline$>7 \mathrm{~mm}$ & 0.66 & $<0.001$ & $0.52-0.82$ & 0.69 & 0.001 & $0.56-0.85$ & 0.69 & 0.001 & $0.55-0.86$ \\
\hline \multicolumn{10}{|l|}{ High WFNS score } \\
\hline Age & 1.12 & 0.003 & $1.04-1.10$ & 1.12 & $<0.001$ & $1.05-1.20$ & 1.11 & 0.002 & $1.04-1.19$ \\
\hline MCA & 1.33 & 0.031 & $1.02-1.72$ & 1.36 & 0.010 & $1.09-1.72$ & 1.33 & 0.019 & $1.05-1.69$ \\
\hline VA & 3.09 & 0.002 & $1.50-6.35$ & 2.89 & 0.001 & $1.57-5.32$ & 2.64 & 0.002 & $1.44-4.83$ \\
\hline BA & 1.72 & 0.012 & $1.13-2.61$ & 1.70 & 0.008 & $1.15-2.51$ & 1.64 & 0.014 & $1.12-2.43$ \\
\hline PICA/AICA/SCA & 1.62 & 0.030 & $1.05-2.50$ & 1.43 & 0.077 & $0.96-2.14$ & 1.47 & 0.063 & $0.98-2.19$ \\
\hline$>7 \mathrm{~mm}$ & 1.54 & $<0.001$ & $1.23-1.93$ & 1.45 & $<0.001$ & $1.18-1.79$ & 1.47 & 0.001 & $1.18-1.83$ \\
\hline \multicolumn{10}{|c|}{ High Fisher grade (grade III-IV) } \\
\hline Age & 1.09 & 0.044 & $1.00-1.17$ & 1.09 & 0.018 & $1.01-1.17$ & 1.08 & 0.042 & $1.00-1.16$ \\
\hline MCA & 1.39 & 0.025 & $1.04-1.85$ & 1.25 & 0.091 & $0.97-1.62$ & 1.22 & 0.139 & $0.94-1.60$ \\
\hline \multicolumn{10}{|c|}{ New focal neurological deficit } \\
\hline Age & 1.12 & 0.016 & $1.02-1.24$ & 1.10 & 0.033 & $1.01-1.19$ & 1.11 & 0.024 & $1.02-1.20$ \\
\hline MCA & 2.17 & $<0.001$ & $1.56-3.03$ & 2.11 & $<0.001$ & $1.56-2.86$ & 2.02 & $<0.001$ & $1.49-2.73$ \\
\hline PCA & 2.53 & 0.049 & $1.00-6.40$ & 2.13 & 0.098 & $0.87-5.19$ & 2.25 & 0.072 & $0.92-5.49$ \\
\hline \multicolumn{10}{|c|}{ New cranial nerve palsy } \\
\hline ICA & 1.62 & 0.026 & $1.06-2.47$ & 1.73 & 0.005 & $1.18-2.52$ & 1.56 & 0.019 & $1.08-2.26$ \\
\hline MCA & 1.92 & 0.001 & $1.31-2.81$ & 2.08 & $<0.001$ & $1.48-2.92$ & 1.84 & 0.001 & $1.30-2.58$ \\
\hline$>7 \mathrm{~mm}$ & 1.76 & 0.001 & $1.20-2.48$ & 1.77 & $<0.001$ & $1.30-2.42$ & 1.64 & 0.003 & $1.19-2.25$ \\
\hline \multicolumn{10}{|l|}{ Thick clot present } \\
\hline Age & 1.21 & 0.002 & $1.07-1.36$ & 1.16 & 0.009 & $1.04-1.29$ & 1.18 & 0.003 & $1.06-1.32$ \\
\hline \multicolumn{10}{|l|}{ Sedated at admission } \\
\hline VA & 3.17 & 0.020 & $1.20-8.39$ & 3.40 & 0.003 & $1.52-7.61$ & 3.21 & 0.002 & $1.53-6.74$ \\
\hline$>7 \mathrm{~mm}$ & 1.45 & 0.032 & $1.03-2.03$ & 1.38 & 0.037 & $1.02-1.88$ & 1.49 & 0.038 & $1.08-2.06$ \\
\hline \multicolumn{10}{|l|}{ Intubed at admission } \\
\hline BA & 1.88 & 0.046 & $1.01-3.50$ & 1.84 & 0.030 & $1.06-3.19$ & 1.58 & 0.100 & $0.94-2.64$ \\
\hline VA & 3.04 & 0.025 & $1.15-8.02$ & 3.27 & 0.004 & $1.46-7.32$ & 2.85 & 0.003 & $1.43-5.67$ \\
\hline$>7 \mathrm{~mm}$ & 1.51 & 0.017 & $1.08-2.11$ & 1.45 & 0.015 & $1.08-1.96$ & 1.59 & 0.002 & $1.22-2.09$ \\
\hline
\end{tabular}

Correlation tables of multivariate analysis (MV), univariate analysis (UV), and analysis of imputed data of missing values (IMP) for correlations with $p$ value $<0.5$. Data was dichotomized into "high" GCS score (GCS $\geq 13$ ) versus "low" GCS score (GCS $\leq 12$ ), high WFNS grade (WFNS grade IV-V) versus low WFNS grade WFNS score (I-III), and high Fisher grade (III-IV) versus low Fisher grade (Fisher grade I-II). Details are provided in Suppl. Data Table 1. Forest plots are provided in Suppl. Data Fig. 1

Further strengths of the present study include its comparatively large-scale dataset that was prospectively provider-collected, nationwide, and hence relatively unselected. This obviates to some extent coding errors, patient selection, and center-specific bias. In addition, data quality was high, and statistical analysis was comprehensive and adjusted for relevant confounders, multiple testing, and missing values. Finally, reporting of data and results is in accordance to the principles of the STROBE statement to minimize the risk of unsaid bias.
We found that the aSAH causing aneurysm's location and size independently predicted the patients' clinical and radiological condition at time point of initial admission to the tertiary referral hospital (Table 4, Suppl. Data Table 1, Suppl. Data Fig. 1). Our results hence support the concept that aneurysm characteristics should be handled as key factors in any potential aSAH-specific outcome assessment tool $[6,18,21]$. That being said, increasing patient age and pre-existing medical conditions have alike been identified as independent predictors for worse outcome following aSAH [7, 21, 33-37]. 
Several attempts have been made over the year to integrate these elements into indexes so as to enhance the ability and the accuracy to predicting the course of the disease (e.g., Charlson comorbidity index [38, 39], SAH [40], FOUR score [41]). Accordingly, we found in our cohort that the older was a patient, the lower was his pre-ictal functional status, and the more likely he presented in poor condition following aSAH (Table 4, Suppl. Data Table 1, Suppl. Data Fig. 1). This being the case, the age at which patients develop a substantial decline in functional status has shifted from around age 50 a decade ago [42], to 60-65 years [7, 43-47], to 70-75 more recently [48] as well as in the present cohort (Table 1).

The question still remains whether there is an age beyond which prognosis become decisively worse [42, 43, 47-51], which means for instance that active aneurysm treatment might be withheld in all patients older than that cutoff age $[52,53]$. We found in our cohort that for instance, about half of patients older than 75 years had favorable outcomepredicting WFNS scores (Suppl. Data Fig. 2B). We hence agree that active treatment should probably not be refused solely on the basis of advanced age [7], but instead suggest that chronological age be taken into consideration along with the patient's pre-ictal functional status when making management decisions and for prognostication $[7,19,21,33,35,36$, 54-57].

\section{Limitations}

Although there is a policy in Switzerland to transfer all aSAH patients to one of the accredited neurovascular centers that participate in the SOS registry, in practice, a fraction of patients may not end up in these centers (e.g., because they die at the admitting hospital from devastating brain hemorrhage of unclear etiology). However, the purpose of this study was not to assess outcome after aSAH, but to determine what factors influence a patient's clinical and radiological status once admitted to a tertiary referral hospital. Besides that, risk factors and co-morbidities such as cigarette smoking and arterial hypertension were not included into our analysis mainly because of missing values in our dataset. However, their influence has been studied elsewhere $[58,59]$. Data quality was comparatively high. Still, there was missing data in our dataset. We compared the results of our regression models with pooled estimates obtained from imputed datasets to reduce the variability of the estimates in our multivariate analysis as well as to investigate whether missing values had introduced bias. We found that there was no relevant difference between coefficients estimated from imputed datasets and those estimated from the dataset restricted to complete cases. Finally, multivariate analyses concerning the impact of the pre-ictal mRS found associations, but ultimately lacked the necessary power to estimate the effect. This indicates that more statistical power is eventually needed, and we suggest that in the future study, cohorts from countries with similar populations and similar treatment standards be merged to obtain valuable additional patients.

\section{Conclusions}

Chronological age should be considered when managing aSAH patients along with multiple other aspects that include aneurysm location, aneurysm size, and pre-ictal functional status that all influence the patients' clinical and radiological condition at admission, and hence the likely course of the disease. However, further research and even larger datasets will be required to determine the extent of associations in representative contemporary aSAH populations.

Acknowledgements To Ethan Taub, MD, for reviewing the manuscript, to Selina Ackermann for editorial assistance, and to the members and collaborators of the Swiss SOS Study group.

Author contributions DZ, MR, RA, HB, LM, and RG designed the study. DZ, MR, SB, MS, CF, DD, NM, AF, MC, DS, JG, DV, TR, RB, MS, JB, and SM carried out sample collection. DZ, MR, RA, and HB performed data analysis. DZ, MR, KB, HB, LM, and RG wrote the manuscript. DZ, MR, RA, HB, KB, and RG revised the manuscript. All authors read and approved the final manuscript.

Funding information This research was supported by departmental funds of the Department of Surgery, Basel University Hospital, Basel, Switzerland. The Basel Institute for Clinical Epidemiology \& Biostatistics receives funding from Stiftung Institut für klinische Epidemiologie.

\section{Compliance with ethical standards}

Statement of human rights Internal Review Board (IRB) and Ethical Committee approval were obtained for all participating centers (under the supervision of the Geneva ethical committee board no. 11-233R, NAC 11-085R). Most local Ethic Committees waived the need for obtaining written informed consent (justification: disproportionality). Written informed consent was obtained however from all participating patients for both the retrospective collection of data in 2009 and the prospective collection of data from 2010 onward if the local Ethic Committee had requested it. As of 2014 (implementation of the new Swiss Human Research Act), written informed consent was obtained from all participating patients in all participating centers. Consent to publish: No consent to publish from the participants to report individual patient data was obtained as no individual participant's data in any form will be published.

Trial registration This study was a retrospective analysis of a prospectively collected database and does not require clinical trial registration.

Conflict of interest The authors declare that they have no conflict of interest. 
Reporting Our results are reported as recommended in the STrengthening the Reporting of OBservational studies in Epidemiology (STROBE) statement.

Availability of data and materials The datasets used and/or analyzed during the present study are available from the corresponding author on reasonable request. Previous presentation: Preliminary results of this study were presented in form of a poster and abstract at the Joint Annual Meeting of the Swiss Society of Neurosurgery and the Swiss Society of Neuroradiology, September 2015, Lucerne, Switzerland.

\section{Appendix: Swiss SOS Study Group}

Members or collaborators of the Swiss SOS Study Group that were not listed as authors include Javier Fandino, Daniel Colluccia, Marta Arrighi, Alice Venier, Dominique E. Kuhlen, Michael Reinert, Astrid Weyerbrock, Martin Hlavica, Jean-Yves Fournier, Andreas Raabe, Juergen Beck, David Bervini, Karl Schaller, Roy T. Daniel, Daniele Starnoni, Mahmoud Messerer, Marc Levivier, Emanuela Keller, Luca Regli, Oliver Bozinov, Sina Finkenstaedt, Luca Remonda, Christoph Stippich, Jan Gralla, Zsolt Kulcsar, Vitor MendesPereira, Alessandro Cianfoni, Peter Ahlborn, Nicolas R. Smoll, Veit Rohde, Sina Tok, Fabian Baumann, Karl Kothbauer, Hassen Kerkeni, Hiroki Dan-Ura, Hans Landolt, Khaled Mostaguir, Yvan Gasche, Asita Sarrafzadeh, Gerhard Hildebrandt, Kerstin Winkler, Christoph Woernle, and Rene Bernays.

\section{References}

1. de Rooij NK, Linn FH, van der Plas JA, Algra A, Rinkel GJ (2007) Incidence of subarachnoid haemorrhage: a systematic review with emphasis on region, age, gender and time trends. J Neurol Neurosurg Psychiatry 78(12):1365-1372. https://doi.org/10.1136/ jnnp.2007.117655

2. Ingall T, Asplund K, Mahonen M, Bonita R (2000) A multinational comparison of subarachnoid hemorrhage epidemiology in the WHO MONICA stroke study. Stroke 31(5):1054-1061. https:// doi.org/10.1161/01.STR.31.5.1054

3. Rinkel GJ, Djibuti M, Algra A, van Gijn J (1998) Prevalence and risk of rupture of intracranial aneurysms: a systematic review. Stroke 29(1):251-256. https://doi.org/10.1161/01.STR.29.1.251

4. Molyneux A, Kerr R, Stratton I, Sandercock P, Clarke M, Shrimpton J, Holman R, International Subarachnoid Aneurysm Trial Collaborative G (2002) International Subarachnoid Aneurysm Trial (ISAT) of neurosurgical clipping versus endovascular coiling in 2143 patients with ruptured intracranial aneurysms: a randomised trial. Lancet 360(9342):1267-1274. https://doi.org/10.1016/S0140-6736(02)11314-6

5. Mugikura S, Takahashi S, Higano S, Shirane R, Sakurai Y, Yamada S (2002) Predominant involvement of ipsilateral anterior and posterior circulations in moyamoya disease. Stroke 33(6):1497-1500. https://doi.org/10.1161/01.STR.0000016828.62708.21

6. Salary M, Quigley MR, Wilberger JE Jr (2007) Relation among aneurysm size, amount of subarachnoid blood, and clinical outcome. J Neurosurg 107(1):13-17. https://doi.org/10.3171/JNS-07/ $07 / 0013$
7. Lanzino G, Kassell NF, Germanson TP, Kongable GL, Truskowski LL, Torner JC, Jane JA (1996) Age and outcome after aneurysmal subarachnoid hemorrhage: why do older patients fare worse? J Neurosurg 85(3):410-418. https://doi.org/10.3171/jns.1996.85.3. 0410

8. Wostrack M, Sandow N, Vajkoczy P, Schatlo B, Bijlenga P, Schaller K, Kehl V, Harmening K, Ringel F, Ryang YM, Friedrich B, Stoffel M, Meyer B (2013) Subarachnoid haemorrhage WFNS grade V: is maximal treatment worthwhile? Acta Neurochir 155(4):579-586. https://doi.org/10.1007/s00701-013-1634-z

9. Rosen DS, Macdonald RL (2005) Subarachnoid hemorrhage grading scales: a systematic review. Neurocrit Care 2(2):110-118. https://doi.org/10.1385/NCC:2:2:110

10. Jaja BNR, Cusimano MD, Etminan N, Hanggi D, Hasan D, Ilodigwe D, Lantigua H, Le Roux P, Lo B, Louffat-Olivares A et al (2013) Clinical prediction models for aneurysmal subarachnoid hemorrhage: a systematic review. Neurocrit Care 18(1):143153. https://doi.org/10.1007/s12028-012-9792-z

11. Teasdale GM, Drake CG, Hunt W, Kassell N, Sano K, Pertuiset B, De Villiers JC (1988) A universal subarachnoid hemorrhage scale: report of a committee of the world federation of neurosurgical societies. J Neurol Neurosurg Psychiatry 51(11):1457. https://doi.org/ 10.1136/jnnp.51.11.1457

12. Teasdale G, Jennett B (1974) Assessment of coma and impaired consciousness. A practical scale. Lancet 2(7872):81-84

13. van Heuven AW, Dorhout Mees SM, Algra A, Rinkel GJ (2008) Validation of a prognostic subarachnoid hemorrhage grading scale derived directly from the Glasgow coma scale. Stroke 39(4):13471348. https://doi.org/10.1161/STROKEAHA.107.498345

14. Fisher CM, Kistler JP, Davis JM (1980) Relation of cerebral vasospasm to subarachnoid hemorrhage visualized by computerized tomographic scanning. Neurosurgery 6(1):1-9. https://doi.org/10. 1227/00006123-198001000-00001

15. Frontera JA, Claassen J, Schmidt JM, Wartenberg KE, Temes R, Connolly ES Jr, MacDonald RL, Mayer SA (2006) Prediction of symptomatic vasospasm after subarachnoid hemorrhage: the modified fisher scale. Neurosurgery 59(1):21-27; discussion 21-27. https://doi.org/10.1227/01.NEU.0000218821.34014.1B

16. Vale FL, Bradley EL, Fisher WS 3rd (1997) The relationship of subarachnoid hemorrhage and the need for postoperative shunting. J Neurosurg 86(3):462-466. https://doi.org/10.3171/jns.1997.86.3. 0462

17. Demirgil BT, Tugcu B, Postalci L, Guclu G, Dalgic A, Oral Z (2003) Factors leading to hydrocephalus after aneurysmal subarachnoid hemorrhage. Minim Invasive Neurosurg 46(6):344 348. https://doi.org/10.1055/s-2003-812500

18. Mocco J, Ransom ER, Komotar RJ, Schmidt JM, Sciacca RR, Mayer SA, Connolly ES Jr (2006) Preoperative prediction of long-term outcome in poor-grade aneurysmal subarachnoid hemorrhage. Neurosurgery 59(3):529-538; discussion 529-538. https:// doi.org/10.1227/01.NEU.0000228680.22550.A2

19. Rosen DS, Macdonald RL (2004) Grading of subarachnoid hemorrhage: modification of the world World Federation of Neurosurgical Societies scale on the basis of data for a large series of patients. Neurosurgery 54(3):566-575; discussion 575-566. https://doi.org/ 10.1227/01.NEU.0000108862.32404.A5

20. Taki W, Sakai N, Suzuki H, Group P (2011) Determinants of poor outcome after aneurysmal subarachnoid hemorrhage when both clipping and coiling are available: Prospective Registry of Subarachnoid Aneurysms Treatment (PRESAT) in Japan. World Neurosurg 76(5):437-445. https://doi.org/10.1016/j.wneu.2011. 04.026

21. Lagares A, Gómez PA, Lobato RD, Alén JF, Alday R, Campollo J (2001) Prognostic factors on hospital admission after spontaneous subarachnoid haemorrhage. Acta Neurochir 143(7):665-672. https://doi.org/10.1007/s007010170044 
22. Pierot L, Cognard C, Anxionnat R, Ricolfi F, Investigators C (2010) Ruptured intracranial aneurysms: factors affecting the rate and outcome of endovascular treatment complications in a series of 782 patients (CLARITY study). Radiology 256(3):916-923. https://doi. org/10.1148/radiol.10092209

23. Ruiz-Sandoval JL, Cantu C, Chiquete E, Leon-Jimenez C, Arauz A, Murillo-Bonilla LM, Villarreal-Careaga J, Barinagarrementeria F, Investigators R (2009) Aneurysmal subarachnoid hemorrhage in a Mexican multicenter registry of cerebrovascular disease: the RENAMEVASC study. J Stroke Cerebrovasc Dis 18(1):48-55. https://doi.org/10.1016/j.jstrokecerebrovasdis.2008.09.019

24. Lagares A, de Toledo P, Fernandez-Alen JA, Ibanez J, Arikan F, Sarabia R, Ballenilla F, Gabarros A, Horcajadas A, Rodriguez-Boto G et al (2008) Spontaneous Subarachnoid Haemorrhage multicenter database from the Group for the Study of Vascular Pathology of the Spanish Society for Neurosurgery: presentation, inclusion criteria and development of an internet-based registry. Neurocirugia (Astur) 19(5):405-415. https://doi.org/10.1016/ S1130-1473(08)70207-0

25. Jaja BN, Attalla D, Macdonald RL, Schweizer TA, Cusimano MD, Etminan N, Hanggi D, Hasan D, Johnston SC, Le Roux P et al (2014) The Subarachnoid Hemorrhage International Trialists (SAHIT) Repository: advancing clinical research in subarachnoid hemorrhage. Neurocrit Care 21(3):551-559. https://doi.org/10. 1007/s12028-014-9990-y

26. Macdonald RL, Cusimano MD, Etminan N, Hanggi D, Hasan D, Ilodigwe D, Jaja B, Lantigua H, Le Roux P, Lo B et al (2013) Subarachnoid Hemorrhage International Trialists data repository (SAHIT). World Neurosurg 79(3-4):418-422. https://doi.org/10. 1016/j.wneu.2013.01.006

27. Ikawa F, Ohbayashi N, Imada Y, Matsushige T, Kajihara Y, Inagawa T, Kobayashi S (2004) Analysis of subarachnoid hemorrhage according to the Japanese standard stroke registry studyincidence, outcome, and comparison with the International Subarachnoid Aneurysm Trial. Neurol Med Chir (Tokyo) 44(5): 275-276. https://doi.org/10.2176/nmc.44.275

28. Fischer T, Johnsen SP, Pedersen L, Gaist D, Sorensen HT, Rothman KJ (2005) Seasonal variation in hospitalization and case fatality of subarachnoid hemorrhage - a nationwide Danish study on 9,367 patients. Neuroepidemiology 24(1-2):32-37. https://doi.org/10. $1159 / 000081047$

29. Schatlo B, Fung C, Fathi AR, Sailer M, Winkler K, Daniel RT, Bijlenga P, Ahlborn P, Seule M, Zumofen D, Reinert M, Woernle C, Stienen M, Levivier M, Hildebrandt G, Mariani L, Bernays R, Fandino J, Raabe A, Keller E, Schaller K (2012) Introducing a nationwide registry: the Swiss study on aneurysmal subarachnoid haemorrhage (Swiss SOS). Acta Neurochir 154(12):2173-2178; discussion 2178. https://doi.org/10.1007/s00701-012-1500-4

30. Bederson JB, Connolly ES Jr, Batjer HH, Dacey RG, Dion JE, Diringer MN, Duldner JE Jr, Harbaugh RE, Patel AB, Rosenwasser RH et al (2009) Guidelines for the management of aneurysmal subarachnoid hemorrhage: a statement for healthcare professionals from a special writing group of the Stroke Council, American Heart Association. Stroke 40(3):994-1025. https://doi. org/10.1161/STROKEAHA.108.191395

31. Farrell B, Godwin J, Richards S, Warlow C (1991) The United Kingdom transient ischaemic attack (UK-TIA) aspirin trial: final results. J Neurol Neurosurg Psychiatry 54(12):1044-1054. https:// doi.org/10.1136/jnnp.54.12.1044

32. Bonferroni C (1937) Teoria statistica delle classi e calcolo delle probabilita. In: Volume in Onore di Ricarrdo dalla Volta. Universita di Firenza, pp 1-62

33. Rosengart AJ, Schultheiss KE, Tolentino J, Macdonald RL (2007) Prognostic factors for outcome in patients with aneurysmal subarachnoid hemorrhage. Stroke 38(8):2315-2321. https://doi.org/ 10.1161/STROKEAHA.107.484360
34. Deruty R, Pelissou-Guyotat I, Mottolese C, Amat D, Bognar L (1995) Level of consciousness and age as prognostic factors in aneurysmal SAH. Acta Neurochir 132(1-3):1-8. https://doi.org/ 10.1007/BF01404840

35. Rabinstein AA, Friedman JA, Nichols DA, Pichelmann MA, McClelland RL, Manno EM, Atkinson JL, Wijdicks EF (2004) Predictors of outcome after endovascular treatment of cerebral vasospasm. AJNR Am J Neuroradiol 25(10):1778-1782

36. Risselada R, Lingsma HF, Bauer-Mehren A, Friedrich CM, Molyneux AJ, Kerr RS, Yarnold J, Sneade M, Steyerberg EW, Sturkenboom MC (2010) Prediction of 60 day case-fatality after aneurysmal subarachnoid haemorrhage: results from the International Subarachnoid Aneurysm Trial (ISAT). Eur J Epidemiol 25(4):261-266. https://doi.org/10.1007/s10654-0109432-x

37. Avdagic SS, Brkic H, Avdagic H, Smajic J, Hodzic S (2015) Impact of comorbidity on early outcome of patients with subarachnoid hemorrhage caused by cerebral aneurysm rupture. Med Arch 69(5):280-283. https://doi.org/10.5455/medarh.2015.69.280-283

38. Boogaarts HD, Conde MP, Janssen E, van Nuenen WF, de Vries J, Donders R, Westert GP, Grotenhuis JA, Bartels RH (2014) The value of the Charlson co-morbidity index in aneurysmal subarachnoid haemorrhage. Acta Neurochir 156(9):1663-1667. https://doi. org/10.1007/s00701-014-2160-3

39. Charlson M, Szatrowski TP, Peterson J, Gold J (1994) Validation of a combined comorbidity index. J Clin Epidemiol 47(11):12451251. https://doi.org/10.1016/0895-4356(94)90129-5

40. Naval NS, Kowalski RG, Chang TR, Caserta F, Carhuapoma JR, Tamargo RJ (2014) The SAH score: a comprehensive communication tool. J Stroke Cerebrovasc Dis 23(5):902-909. https://doi.org/ 10.1016/j.jstrokecerebrovasdis.2013.07.035

41. Zeiler FA, Lo BW, Akoth E, Silvaggio J, Kaufmann AM, Teitelbaum J, West M (2017) Predicting outcome in subarachnoid hemorrhage (SAH) utilizing the full outline of UnResponsiveness (FOUR) score. Neurocrit Care 27(3):381-391. https://doi.org/10. 1007/s12028-017-0396-5

42. Fortuny LA, Adams CB, Briggs M (1980) Surgical mortality in an aneurysm population: effects of age, blood pressure and preoperative neurological state. J Neurol Neurosurg Psychiatry 43(10):879882. https://doi.org/10.1136/jnnp.43.10.879

43. O'Sullivan MG, Dorward N, Whittle IR, Steers AJ, Miller JD (1994) Management and long-term outcome following subarachnoid haemorrhage and intracranial aneurysm surgery in elderly patients: an audit of 199 consecutive cases. Br J Neurosurg 8(1):2330. https://doi.org/10.3109/02688699409002389

44. Ryttlefors M, Enblad P, Kerr RS, Molyneux AJ (2008) International subarachnoid aneurysm trial of neurosurgical clipping versus endovascular coiling: subgroup analysis of 278 elderly patients. Stroke 39(10):2720-2726. https://doi.org/10.1161/STROKEAHA. 107.506030

45. Rowe JG, Molyneux AJ, Byrne JV, Renowden S, Aziz TZ (1996) Endovascular treatment of intracranial aneurysms: a minimally invasive approach with advantages for elderly patients. Age Ageing 25(5):372-376. https://doi.org/10.1093/ageing/25.5.372

46. Laidlaw JD, Siu KH (2003) Poor-grade aneurysmal subarachnoid hemorrhage: outcome after treatment with urgent surgery. Neurosurgery 53(6):1275-1280; discussion 1280-1272. https:// doi.org/10.1227/01.NEU.0000093199.74960.FF

47. Kazumata K, Kamiyama H, Ishikawa T (2006) Reference table predicting the outcome of subarachnoid hemorrhage in the elderly, stratified by age. J Stroke Cerebrovasc Dis 15(1):14-17. https://doi. org/10.1016/j.jstrokecerebrovasdis.2005.08.007

48. Nieuwkamp DJ, Rinkel GJ, Silva R, Greebe P, Schokking DA, Ferro JM (2006) Subarachnoid haemorrhage in patients $>$ or $=75$ years: clinical course, treatment and outcome. J Neurol Neurosurg 
Psychiatry 77(8):933-937. https://doi.org/10.1136/jnnp.2005. 084350

49. Ryttlefors M, Howells T, Ronne-Engstrom E, Nilsson P, Enblad P (2010) Neurointensive care is justified in elderly patients with severe subarachnoid hemorrhage - an outcome and secondary insults study. Acta Neurochir 152(2):241-249; discussion 249. https://doi. org/10.1007/s00701-009-0496-x

50. Awe OO, Gonzalez LF, Hasan D, Maltenfort M, Rossenwasser R, Jabbour P (2011) Treatment outcome of aneurysmal subarachnoid hemorrhage in patients aged 70 years and older. Neurosurgery 68(3):753-758; discussion 758. https://doi.org/10.1227/NEU. $0 \mathrm{~b} 013 \mathrm{e} 318207 \mathrm{a} 9 \mathrm{fb}$

51. Horiuchi T, Tanaka Y, Hongo K (2005) Surgical treatment for aneurysmal subarachnoid hemorrhage in the 8th and 9th decades of life. Neurosurgery 56(3):469-475; discussion 469-475. https://doi. org/10.1227/01.NEU.0000153926.67713.B8

52. Al-Khindi T, Macdonald RL, Schweizer TA (2010) Cognitive and functional outcome after aneurysmal subarachnoid hemorrhage. Stroke 41(8):e519-e536. https://doi.org/10.1161/STROKEAHA. 110.581975

53. Vlak MH, Rinkel GJ, Greebe P, Greving JP, Algra A (2013) Lifetime risks for aneurysmal subarachnoid haemorrhage: multivariable risk stratification. J Neurol Neurosurg Psychiatry 84(6): 619-623. https://doi.org/10.1136/jnnp-2012-303783
54. Juvela S (2003) Prehemorrhage risk factors for fatal intracranial aneurysm rupture. Stroke 34(8):1852-1857. https://doi.org/10. 1161/01.STR.0000080380.56799.DD

55. Kassell NF, Torner JC, Haley EC, Jane JA, Adams HP, Kongable GL (1990) The international cooperative study on the timing of aneurysm surgery. Part 1: overall management results. J Neurosurg 73(1):18-36. https://doi.org/10.3171/jns.1990.73.1. 0018

56. Eskesen V, Rosenorn J, Schmidt K, Ronde F (1987) Pre-existing arterial hypertension in subarachnoid haemorrhage: an unfavourable prognostic factor. Br J Neurosurg 1(4):455-461. https://doi.org/10.3109/02688698708999636

57. Germanson TP, Lanzino G, Kongable GL, Torner JC, Kassell NF (1998) Risk classification after aneurysmal subarachnoid hemorrhage. Surg Neurol 49(2):155-163. https://doi.org/10.1016/S00903019(97)00337-6

58. Juvela S (1992) Alcohol consumption as a risk factor for poor outcome after aneurysmal subarachnoid haemorrhage. BMJ 304(6843):1663-1667. https://doi.org/10.1136/bmj.304.6843.1663

59. Kongable GL, Lanzino G, Germanson TP, Truskowski LL, Alves WM, Torner JC, Kassell NF (1996) Gender-related differences in aneurysmal subarachnoid hemorrhage. J Neurosurg 84(1):43-48. https://doi.org/10.3171/jns.1996.84.1.0043

\section{Affiliations}

Daniel W. Zumofen ${ }^{1,2} \cdot$ Michel Roethlisberger $^{1} \cdot$ Rita Achermann $^{3} \cdot$ Schatlo Bawarjan $^{4} \cdot$ Martin N. Stienen $^{5}$. Christian Fung ${ }^{6}$ - Donato D'Alonzo ${ }^{7}$. Nicolai Maldaner ${ }^{5} \cdot$ Andrea Ferrari $^{8} \cdot$ Marco V. Corniola ${ }^{9} \cdot$ Daniel Schoeni $^{6}$. Johannes Goldberg ${ }^{6}$. Daniele Valsecchi ${ }^{10} \cdot$ Thomas Robert $^{10} \cdot$ Rodolfo Maduri $^{11} \cdot$ Martin Seule $^{8}$. Jan-Karl Burkhardt ${ }^{12}$. Serge Marbacher ${ }^{7}$. Philippe Bijlenga ${ }^{9} \cdot$ Kristine A. Blackham $^{2} \cdot$ Heiner C. Bucher $^{3}$. Luigi Mariani $^{1}$ • Raphael Guzman ${ }^{1}$

1 Department of Neurosurgery, University Hospital Basel, Spitalstrasse 21, CH-4031 Basel, Switzerland

2 Department of Radiology, Division of Diagnostic and Interventional Neuroradiology, University Hospital Basel, Petersgraben 4, CH4031 Basel, Switzerland

3 Department Institute for Clinical Epidemiology and Biostatistics, University Hospital Basel, Spitalstrasse 12, CH4031 Basel, Switzerland

4 Department of Neurosurgery, University Hospital Göttingen, Robert Koch Strasse 40, 37075 Göttingen, Germany

5 Department of Neurosurgery, University Hospital Zurich, Rämistrasse 100, CH-8091 Zurich, Switzerland

6 Department of Neurosurgery, Inselspital, University of Bern, Freiburgstrasse 16, CH-3010 Bern, Switzerland
7 Department of Neurosurgery, Kantonsspital Aarau, Tellstrasse 25, CH-5001 Aarau, Switzerland

8 Department of Neurosurgery, Kantonsspital St. Gallen, Rorschacher Strasse 95, CH-9007 St.Gallen, Switzerland

9 Department of Neurosurgery, Hopitaux Universitaires Genève, Rue Gabrielle-Perret-Gentil 4, CH-1205 Geneva, Switzerland

10 Department of Neurosurgery, Ospedale Civico di Lugano, Via Tesserete 46, CH-6900 Lugano, Switzerland

11 Service of Neurosurgery, Department of Clinical Neurosciences, University Hospital of Lausanne, Rue du Bugnon 46, CH1011 Lausanne, Switzerland

12 Department of Neurological Surgery, University of California San Francisco, 505 Parnassus Avenue, San Francisco, CA 94143-0112, USA 